\title{
Involvement of the Nervous System in SARS-CoV-2 Infection
}

\author{
Hao $\mathrm{Li}^{1} \cdot$ Qun Xue ${ }^{1} \cdot$ Xingshun $\mathrm{Xu}^{1,2,3}$
}

Received: 7 April 2020 /Revised: 22 April 2020 / Accepted: 24 April 2020 /Published online: 13 May 2020

(C) Springer Science+Business Media, LLC, part of Springer Nature 2020

\begin{abstract}
As a severe and highly contagious infectious disease, coronavirus disease 2019 (COVID-19) has caused a global pandemic. Several case reports have demonstrated that the respiratory system is the main target in patients with COVID-19, but the disease is not limited to the respiratory system. Case analysis indicated that the nervous system can be invaded by severe acute respiratory syndrome coronavirus 2 (SARS-CoV-2) and that $36.4 \%$ of COVID-19 patients had neurological symptoms. Importantly, the involvement of the CNS may be associated with poor prognosis and disease worsening. Here, we discussed the symptoms and evidence of nervous system involvement (directly and indirectly) caused by SARS-CoV-2 infection and possible mechanisms. CNS symptoms could be a potential indicator of poor prognosis; therefore, the prevention and treatment of CNS symptoms are also crucial for the recovery of COVID-19 patients.
\end{abstract}

Keywords SARS-CoV-2 $\cdot$ COVID-19 $\cdot$ Central nervous system $\cdot$ Infection

\section{Introduction}

In December 2019, Dr. Li Wenliang, an ophthalmologist in Wuhan Central Hospital, sent the first signal of an outbreak of suspected severe acute respiratory syndrome-like disease (Petersen et al. 2020). Then, Chinese scientists responded quickly and performed next-generation sequencing for clinical samples from patients with this unknown pneumonia; they found a new coronavirus, later named severe acute respiratory syndrome coronavirus 2 (SARS-CoV-2) by the International Committee on Taxonomy of Viruses (Coronaviridae Study Group of the International Committee on Taxonomy of 2020), and published the virus RNA sequence in the public database(Wu et al. 2020). On February 11, 2020, the World Health Organization named this infection coronavirus disease-

Qun Xue

qxue_sz@163.com

Xingshun Xu

xingshunxu@suda.edu.cn

1 Department of Neurology, The First Affiliated Hospital of Soochow University, Suzhou 215004, Jiangsu, China

2 Institute of Neuroscience, Soochow University, Suzhou 215123, Jiangsu, China

3 Jiangsu Key Laboratory of Neuropsychiatric Diseases, Soochow University, Suzhou 215123, Jiangsu, China
2019 (COVID-19) (Lai et al. 2020a). Although the mortality rate of COVID-19 is currently lower than that of SARS, as of April 16, 2020, COVID-19 has causing more than 2 million cases and over 137 thousand deaths (Bulut and Kato 2020). Therefore, COVID-19 has become a global public health problem, and the World Health Organization classifies the global threat level of coronavirus as very high and designated the COVID-19 outbreak a pandemic (Bulut and Kato 2020). Growing evidence indicates that SARS-CoV-2 also affects different organs and systems, including the central nervous system (CNS). Here, we summarized the evidence on the involvement of the nervous system in SARS-CoV-2 infection and discussed the possible mechanisms of CNS infection.

\section{Symptoms of SARS-CoV-2 Infection}

An increasing number of cases of SARS-CoV-2 infection have been reported; in addition to the main symptoms of the respiratory system, such as fever, cough, and breathing difficulty, other systemic symptoms have been described. As in a recent case analysis of 55,924 laboratory-confirmed cases, symptoms and signs included fever (87.9\%), dry cough (67.7\%), fatigue (38.1\%), sputum production (33.4\%), shortness of breath (18.6\%), sore throat (13.9\%), headache (13.6\%), myalgia or joint pain (14.8\%), chills (11.4\%), nausea or vomiting $(5.0 \%)$, nasal congestion (4.8\%), diarrhea (3.7\%), 
hemoptysis $(0.9 \%)$, and conjunctival hyperemia $(0.8 \%)(\mathrm{Hu}$ and Li 2020). In a clinical analysis of 138 patients with COVID-19, the most common symptoms were fever (98.6\%), fatigue $(69.6 \%)$, dry cough $(59.4 \%)$, myalgia $(34.8 \%)$, dyspnea $(31.2 \%)$, diarrhea $(10.1 \%)$, nausea $(10.1 \%)$, dizziness $(9.4 \%)$, headache $(6.5 \%)$, vomiting (3.6\%), and abdominal pain (2.2\%) (Wang et al. 2020). In addition, lymphopenia occurred in $70.3 \%$ (97 cases) of patients, and prolonged prothrombin time was found in 58\% (80 cases) of patients (Wang et al. 2020). In another clinical study, the clinical manifestations in 99 laboratory-confirmed patients were fever $(83 \%)$, cough $(82 \%)$, shortness of breath $(31 \%)$, muscle pain $(11 \%)$, mental disorder $(9 \%)$, headache $(8 \%)$, sore throat $(5 \%)$, runny nose $(4 \%)$, chest pain $(2 \%)$, diarrhea (2\%), and nausea and vomiting (1\%) (Chen et al. 2020a). Furthermore, in a report of 140 patients, the most common symptoms were fever (91.7\%), followed by cough (75\%), fatigue (75\%), and chest tightness or dyspnea (36.7\%). Of these patients, $39.6 \%$ complained about gastrointestinal symptoms, including nausea (17.3\%), diarrhea (12.9\%), anorexia $(12.2 \%)$, abdominal pain $(5.8 \%)$, belching $(5 \%)$, and emesis (5\%) (Zhang et al. 2020). In addition, lymphopenia occurred in $75.4 \%$ of these patients (Zhang et al. 2020). In a report from a non-core epidemic area, the most common symptoms of laboratory-confirmed patients were fever (77\%), cough $(81 \%)$, expectoration $(56 \%)$, headache $(34 \%)$, myalgia or fatigue $(52 \%)$, diarrhea $(8 \%)$, hemoptysis $(3 \%)$, and shortness of breath (3\%) (Xu et al. 2020b). Therefore, SARS-CoV-2 infection involves multiple tissues and systems; the symptoms and severity of different systems depend on the tissue sensitivity to viral infection. In addition, for different populations, symptom severity may be related to the immune response. After infection, immunity is decreased in the early phase, and lymphocyte counts are reduced in the peripheral blood of patients with COVID-19 (Huang et al. 2020a; Zhang et al. 2020). It is worth noting that some patients have no obvious symptoms, even though the results of nucleic acid testing for SARS-CoV-2 are positive (Tong et al. 2020; Wang et al. 2020); these patients should receive additional attention because they can transmit the virus to more people.

\section{Clinical Symptoms and Evidence of Nervous System Involvement after SARS-CoV-2 Infection}

In recent case reports, in addition to respiratory system symptoms such as fever, chills, cough, sputum production, shortness of breath, sore throat, nausea or vomiting, and nasal congestion, the second most common system symptoms were sometimes nervous system symptoms, including headache, nausea, vomiting, dizziness, myalgia, and fatigue. Nausea and vomiting could be the symptoms of either digestive system or nervous system, but if these symptoms combined with headache or high intracranial pressure, these may suggest the symptoms of the CNS infection. Increasing evidence has demonstrated that SARS-CoV-2 has the ability to invade the nervous system. In a retrospective case study of 214 hospitalized patients with COVID-19 in Wuhan, China, more than $36.4 \%$ of patients were found to have acute cerebrovascular disease, disturbance of consciousness, and skeletal muscle damage as well as neurological manifestations, such as dizziness, headache, nausea, hypogeusia, and hyposmia (Mao et al. 2020). The authors concluded that neurologic manifestations should be given more attention (Mao et al. 2020). One patient experienced frequent maxillofacial and angular twitching with persistent hiccups at 2 weeks after disease onset; physical examination revealed positive neck resistance, slow response to light, increased muscle tension in the limbs, and bilateral ankle clonus. In addition, the results of cerebrospinal fluid (CSF) analysis showed high pressure $\left(330 \mathrm{mmH}_{2} \mathrm{O}\right)$. The patient was diagnosed with encephalitis. Next-generation sequencing of CSF samples confirmed the existence of SARSCoV-2 infection in the CNS (Xiang et al. 2020). Recently, another case of encephalitis caused by SARS-CoV-2 was also reported (Moriguchi et al. 2020). The patient had a stiff neck and unconsciousness on the ninth day after symptom onset. CSF pressure was high $\left(320 \mathrm{mmH}_{2} \mathrm{O}\right)$. Interestingly, SARSCoV-2 RNA was not detected in the samples from nasopharyngeal swabs, but CSF samples (Moriguchi et al. 2020). In addition to the most common symptoms of cranial hypertension, such as headache, nausea, and vomiting, some patients also have neurological symptoms, such as dizziness, fatigue, and insanity (Chen et al. 2020a; Huang et al. 2020a; Mao et al. 2020). According to recent studies, SARS-CoV-2 infection caused the spectrum of neurological diseases including viral encephalitis, meningoencephalitis, ischemic stroke, and hemorrhagic stroke (Mao et al. 2020; Moriguchi et al. 2020; Xiang et al. 2020). Among patients, most cases were acute cerebrovascular diseases. These studies provided evidence for SARS$\mathrm{CoV}-2$ infection in the CNS. CNS involvement indicated poor prognosis, worsened clinical condition, and sudden death (Mao et al. 2020).

Previous studies on the SARS epidemic showed that symptoms including anxiety, depression, stress, and posttraumatic stress disorder were present in of SARS survivors and medical care worker (Du et al. n.d.; Yang et al. 2003). The COVID-19 epidemic is a source of more stress than the SARS epidemic, and SARS-CoV-2-caused psychological risks should be taken seriously (Bao et al. 2020; Kang et al. 2020). Actually, local and national mental health institutions of China have noted that patients with mental dysfunction should be properly treated (Lai et al. 2020b). Psychological problems, such as anxiety, depression, insomnia, and distress have been reported (Lai et al. 2020b). Some patients with COVID-19 were found to be mentally deranged (9\%) (Chen et al. 2020a). On the 
psychological evaluation of 89 patients with COVID-19, 52\% had no psychological symptoms, $35 \%$ had mild symptoms, and $13 \%$ had moderate to severe symptoms (Xu et al. 2020a). In a survey of 230 medical staff, the incidence of anxiety was $23.04 \%$, and the incidence of severe anxiety, moderate anxiety, and mild anxiety was $2.17 \%, 4.78 \%$, and $16.09 \%$, respectively; the incidence of stress disorders among medical staff was $27.39 \%$, and women had a higher incidence than men (Huang et al. 2020b). Some medical staff showed signs of excitement, irritability, reluctance to rest, and psychological distress in response to the outbreak, but they refused to admit psychological distress and receive any psychological help (Chen et al. 2020b). Additionally, posttraumatic stress disorder (PTSD) was the most severe outcome in patients and medical care workers after the SARS epidemic (Maunder 2009). Therefore, in response to the COVID-19 epidemic, psychiatric and psychological problems are an important issue in patients and medical staff.

\section{Possible Mechanisms of Neurological Symptoms}

SARS-CoV-2 is a Betacoronavirus with a single-stranded, enveloped RNA belonging to the Sarbecovirus subgenus of the Coronaviridae family (Chan et al. 2020). Its RNA genome is 29,891 nucleotides in size, encoding 9860 amino acids (Chan et al. 2020). Because the similarity of RNA sequences between SARS-CoV-2 and SARS-CoV is as high as 79.5\% (Zhou et al. 2020), the mechanisms of SARS-CoV-2 infection may be similar to those of SARS-CoV infection. Angiotensinconverting enzyme 2 (ACE2), which is abundantly expressed on the cell surface of many human organs (Hamming et al. 2004), is a target of SARS-CoV infection, with the help of the serine protease TMPRSS2 (Hamming et al. 2004; Hoffmann et al. 2020). A recent study demonstrated that ACE2 is also considered to be a functional receptor for SARS-CoV-2 invasion (Zou et al. 2020). SARS-CoV-2 binds to the host cells' ACE2 and infects the cells; SARS-CoV-2 sheds nucleic acid from the host to spread, similar to influenza virus, but its pattern of detachment does not seem to be the same as that of SARS-CoV (Zou et al. 2020). SARS-CoV-2 possesses more powerful pathogenicity and transmissibility than SARS-CoV and MERS-CoV, because SARS-CoV-2 and ACE2 have a stronger binding capacity (Zou et al. 2020).

A previous study showed that ACE2 is expressed in the CNS under physiological conditions (Hamming et al. 2004). It is unknown whether ACE2 expression is induced under pathological conditions such as SARS-COV-2 infection. Because of the existence of ACE2 in the CNS, it is possible to induce SARS-CoV-2 invasion via ACE2 on the neuronal cell membrane and cause brain injury and neurological symptoms. According to a previous study on coronavirus, the S1 unit of the spike protein on the surface of the coronavirus binds to the neuronal ACE2 receptor and attaches to the surface of target cells; then, the serine protease TMPRSS2 activates the spike protein, and the virus enters the neuron (Hoffmann et al. 2020). In addition, endothelial cells of blood vessels have high expression of ACE2, and SARS-CoV-2 infection can attack endothelial cells in the cerebral blood vessels through the ACE2 receptor and disrupt the blood-brain barrier (BBB), resulting in increased permeability of the $\mathrm{BBB}$, cerebral edema, and intracranial hypertension. Furthermore, a disrupted BBB may promote invasion into brain tissues and neurons as depicted in Fig. 1a, b. This pattern of CNS invasion was confirmed for other coronaviruses (Bleau et al. 2015; Cowley and Weiss 2010). A previous study identified the presence of SARS-CoV in the hypothalamus and cortical neurons of patients with SARS (Ding et al. 2004). In addition to invasion by blood vessels, viruses may enter the CNS through the terminals of the olfactory nerve (Arbour et al. 1999). Importantly, axonal transport also supports the rapid spread from neuron to neuron (Dubé et al. 2018). A recent study showed that almost no virus particles were detected in nonneuronal cells in infected brain areas (Li et al. 2020). Therefore, brain damage may also be caused by cytokines secreted from infected neurons, especially when the virus invades the nervous system in susceptible individuals with low immunity to this virus (Desforges et al. 2014; Skinner et al. 2019). However, these speculations need additional investigation in SARS-CoV-2 infection.

With the increasing awareness of autoantibody-positive cases, autoimmune encephalitis has received increasing attention (Dubey et al. 2018). This autoimmune disease is related to genetic susceptibility, infection, and stressful life events, and is caused by excessive self-response and antigen-driven immune responses (David et al. 2018; Karagianni et al. 2019; Skopouli and Katsiougiannis 2018). In patients with SARS, autoantibodies against the coronavirus spike protein were found to react with human epithelial cells and endothelial cells, and cause cytotoxicity (Lin et al. 2005; Yang et al. 2005). Therefore, similarly, patients with SARS-CoV-2 infection may produce antibodies to fight against SARS-CoV-2 but that also attack antigens in human endothelial cells in cerebral vessels or neurons through the disrupted BBB, which results in cerebral edema and autoimmune encephalitis as shown in Fig. 1c.

\section{Possible Mechanisms of Psychiatric Symptoms}

During the COVID-19 pandemic, environmental stress such as the fear to be affected, quarantine, the experience of breath difficulty, or all kinds of complains in patients leads to different psychiatric disorders as similar to those in SARS epidemic (Maunder 2009). Under these situations, stressor-dependent corticotrophin-releasing hormone $(\mathrm{CRH})$ is released from hypothalamic paraventricular nucleus (PVN) neurons in susceptible individuals and further activates the hypothalamicpituitary-adrenal (HPA) axis by binding to the CRH receptors in the anterior pituitary gland to stimulate the release of 

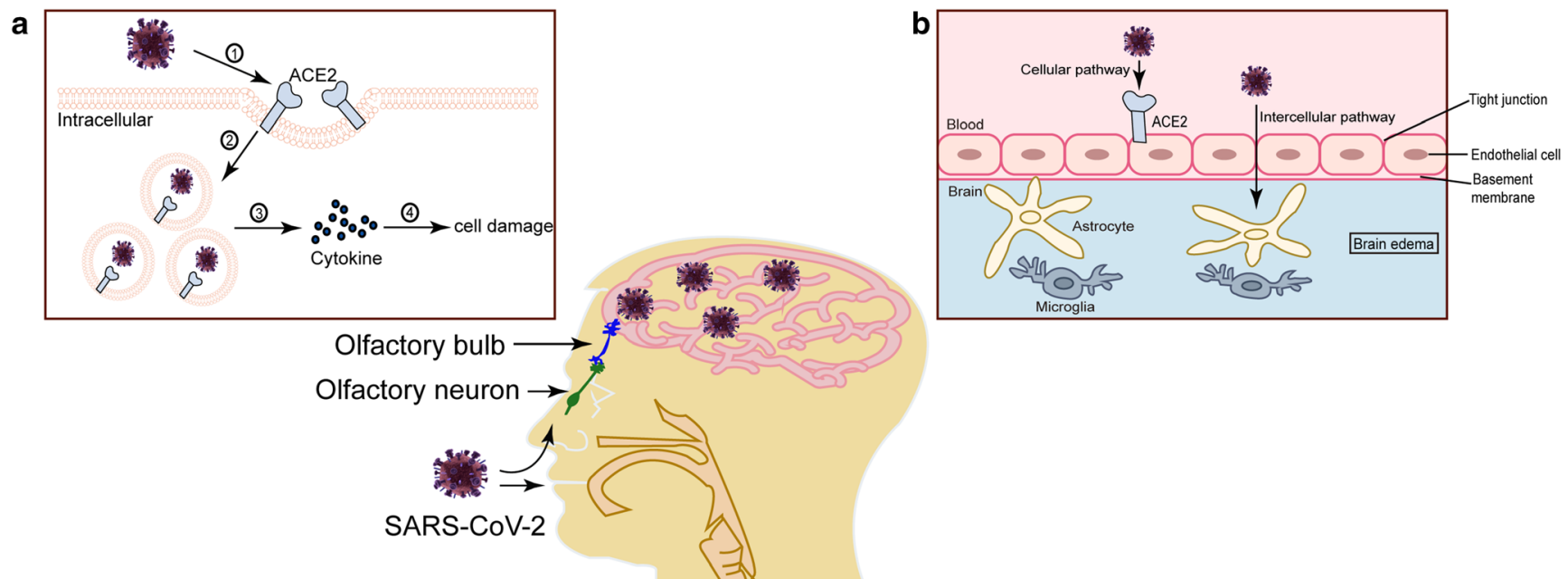

C

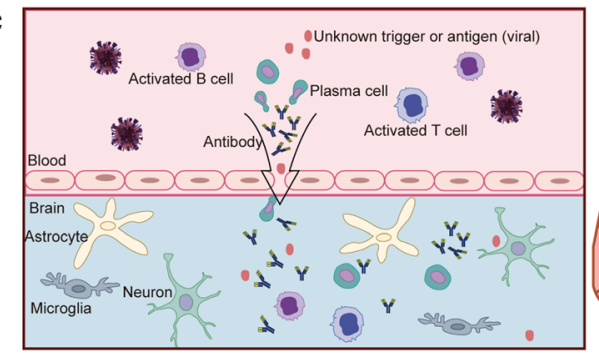

Fig. 1 Possible mechanisms of SARS-CoV-2 infection-related CNS symptoms. a SARS-CoV-2 may enter the brain through the olfactory nerve endings and directly infect neurons via ACE2 protein on the surface of neurons. Axonal transport may promote the rapid spread of neurons to neurons. Also, cytokines secreted from infected neurons damage nearby neurons and glial cells. b SARS-CoV-2 may enter the blood vessels through mucosa and infected lungs. SARS-CoV-2 binds to ACE2 protein that is abundantly expressed in endothelial cells, disrupting endothelial cells and the blood-brain barrier and leading to cerebral edema and intracranial hypertension. c After SARS-CoV-2 infection, human immune cells produce antibodies against this coronavirus; however, some adrenocorticotropic hormone (ACTH) (Futch et al. 2017; Kumar et al. 2013; Sanders and Nemeroff 2016; Soria et al. 2018). The increase of serum ACTH promotes the elevation of concentration of glucocorticoids in the blood (Curtin et al. 2009; Noisakran et al. 1998). Under the stimulation of ACTH, high levels of glucocorticoids are secreted into the systemic circulation and exert its role by binding to glucocorticoid receptors (GR) in different organs such as the brain (Herman et al. 2016). The over-activation of the HPA axis effectors glucocorticoids and GR causes stress-related gene expression and exhibit different behaviors (De Kloet et al. 1998; Herman et al. 2016). In addition to the over-activation of the HPA axis, stress-related gene dysfunction increased the susceptibility in response to environmental stress such as the polymorphism of SERT, BDNF, GR, FKBP5, and CRHR1 genes (Ding and Dai 2019). Environmental stress can alter the epigenetics of these genes through different mechanisms such as DNA methylation, chromatin modification, and histone deacetylation, and causes the transcriptional changes of these gene expression, resulting in stress-related disorders (Cheng et al. 2018; Prasad et al. 2019; Ryan et al. 2016). Therefore, under the situation of COVID-19 pandemic, severe environmental stress including psychological stress may cause different psychiatric disorders through the activation of the HPA axis and altered epigenetic modifications of stressrelated genes (as shown in Fig. 1d). In addition, stress may also increase the susceptibility to SARS-CoV-2 infection and aggravating the disease process (Glaser and Kiecolt-Glaser and Kiecolt-Glaser 2005; Yan et al. 2020).

\section{Therapeutic Strategies for CNS Symptoms}

During this emerging epidemic, currently, the most effective method may be to develop vaccines to SARS-CoV-2 (Patel and Jernigan 2020; Zhang and Liu 2020), but this approach takes some time. Although some possible diagnostic protocols have been published (Beigel et al. 2019; Gao et al. 2020; Xiao 
et al. 2020), no antiviral drugs have yet been reported to be clinically effective. Once CNS symptoms occur during SARS-CoV-2 infection, active antiviral and symptomatic supportive treatment should be used to stabilize the internal environment and maintain vital signs. Special attention should be paid to decreasing intracranial hypertension by using dehydrating agents such as mannitol and furosemide. A recent study also proposed that the CNS infection of SARS-CoV-2 was partially responsible for acute respiratory failure in patients (Li et al. 2020). Therefore, prevention and treatment of the CNS infection may be important to reduce respiratory symptoms and acute respiratory failure as well as improve the prognosis of COVID-19.

In addition, the psychological pressure caused by SARS$\mathrm{CoV}-2$ should be reduced by psychiatrists to prevent worsening of the disease (Bao et al. 2020; Duan and Zhu 2020). The combination of drug treatment and psychotherapy may improve the healing efficiency of patients (Xu et al. 2020a). Some studies have adopted a combination of drug therapy and psychological therapy, and evaluated the HAMD/ HAMA reduction rate; the effective rate of 69 patients after 2 weeks of treatment was $82.3 \%$ (Xu et al. 2020a). A professional psychotherapy team and a psychological intervention team should be very helpful to patients or medical staff for providing psychological counseling (Xiao et al. 2020). Studies have shown that women pay more attention to inner experiences and self-perceptions, and have a higher chance of experiencing psychological problems than men. Therefore, special attention should be given to women (Xu et al. 2020a).

\section{Conclusion}

In this review, we summarized the available data on nervous system symptoms after SARS-CoV-2 infection in patients. A large percentage of patients with COVID-19 presented with central and peripheral nervous system symptoms, such as headache, nausea, vomiting, dizziness, insanity, neck resistance, hypogeusia, and hyposmia, as well as psychiatric and psychological symptoms. Because current case reports have focused mostly on respiratory system symptoms and respiratory failure, neurological symptoms may be neglected, and detailed information is lacking, such as the relationship between headache and nausea/vomiting or intracranial hypertension. However, from the available data, we can conclude that SARS-CoV-2 infection is related to encephalitis, cerebrovascular diseases, consciousness disturbance, anxiety, and depression in patients with COVID-19. Nervous system symptoms are considered a potential indicator of poor prognosis; therefore, prevention and treatment for the CNS symptoms could be crucial for the recovery of COVID-19 patients.
Funding Information This work was supported by the grants from National Key R\&D Program of China (2017YFE0103700), the National Science Foundation of China (81120108011 and 81771454), Shandong Provincial Natural Science Foundation (ZR2019ZD32), the Priority Academic Program Development of Jiangsu Higher Education Institutions of China, the Key R\&D Program of Jiangsu Province (BE2019666), and Suzhou Special Project for Clinical Diagnosis and Treatment of Key Diseases (LCZX201702).

\section{Compliance with Ethical Standards}

Conflict of Interest The authors declare that they have no conflict of interest.

\section{References}

Arbour N, Côté G, Lachance C, Tardieu M, Cashman NR, Talbot PJ (1999) Acute and persistent infection of human neural cell lines by human coronavirus OC43. J Virol 73:3338-3350

Bao Y, Sun Y, Meng S, Shi J, Lu L (2020) 2019-nCoV epidemic: address mental health care to empower society. Lancet (London, England) 395:e37-e38. https://doi.org/10.1016/s0140-6736(20)30309-3

Beigel JH, Nam HH, Adams PL, Krafft A, Ince WL, El-Kamary SS, Sims AC (2019) Advances in respiratory virus therapeutics - a meeting report from the 6th isirv Antiviral Group conference. Antiviral Res 167:45-67. https://doi.org/10.1016/j.antiviral.2019.04.006

Bleau C, Filliol A, Samson M, Lamontagne L (2015) Brain invasion by mouse hepatitis virus depends on impairment of tight junctions and beta interferon production in brain microvascular endothelial cells. $\mathrm{J}$ Virol 89:9896-9908. https://doi.org/10.1128/jvi.01501-15

Bulut C, Kato Y (2020) Epidemiology of COVID-19. Turk J Med Sci 50: 563-570. https://doi.org/10.3906/sag-2004-172

Chan JF, Kok KH, Zhu Z, Chu H, To KK, Yuan S, Yuen KY (2020) Genomic characterization of the 2019 novel human-pathogenic coronavirus isolated from a patient with atypical pneumonia after visiting Wuhan. Emerg Microbes Infect 9:221-236. https://doi.org/10. 1080/22221751.2020.1719902

Chen N et al (2020a) Epidemiological and clinical characteristics of 99 cases of 2019 novel coronavirus pneumonia in Wuhan, China: a descriptive study. Lancet (London, England) 395:507-513. https:// doi.org/10.1016/s0140-6736(20)30211-7

Chen Q et al (2020b) Mental health care for medical staff in China during the COVID-19 outbreak. Lancet Psychiatry 7:e15-e16. https://doi. org/10.1016/s2215-0366(20)30078-x

Cheng Y et al (2018) Ten-eleven translocation proteins modulate the response to environmental stress in mice. Cell Rep 25:3194-3203 e3194. https://doi.org/10.1016/j.celrep.2018.11.061

Coronaviridae Study Group of the International Committee on Taxonomy of V (2020) The species severe acute respiratory syndrome-related coronavirus: classifying 2019-nCoV and naming it SARS-CoV-2. Nat Microbiol 5:536-544. https://doi.org/10.1038/s41564-0200695-z

Cowley TJ, Weiss SR (2010) Murine coronavirus neuropathogenesis: determinants of virulence. J Neurovirol 16:427-434. https://doi. org $/ 10.3109 / 13550284.2010 .529238$

Curtin NM, Boyle NT, Mills KH, Connor TJ (2009) Psychological stress suppresses innate IFN-gamma production via glucocorticoid receptor activation: reversal by the anxiolytic chlordiazepoxide. Brain Behav Immun 23:535-547 doi:https://doi.org/10.1016/j.bbi.2009. 02.003

David T, Ling SF, Barton A (2018) Genetics of immune-mediated inflammatory diseases. Clin Exp Immunol 193:3-12. https://doi.org/10. 1111/cei.13101 
De Kloet ER, Vreugdenhil E, Oitzl MS, Joels M (1998) Brain corticosteroid receptor balance in health and disease. Endocr Rev 19:269-301. https://doi.org/10.1210/edrv.19.3.0331

Desforges M, Le Coupanec A, Brison E, Meessen-Pinard M, Talbot PJ (2014) Neuroinvasive and neurotropic human respiratory coronaviruses: potential neurovirulent agents in humans. Adv Exp Med Biol 807:75-96 doi:https://doi.org/10.1007/978-81-322-177706

Ding Y, Dai J (2019) Advance in stress for depressive disorder. Adv Exp Med Biol 1180:147-178. https://doi.org/10.1007/978-981-32-927108

Ding $\bar{Y}$ et al (2004) Organ distribution of severe acute respiratory syndrome (SARS) associated coronavirus (SARS-CoV) in SARS patients: implications for pathogenesis and virus transmission pathways. J Pathol 203:622-630. https://doi.org/10.1002/path.1560

Du L, J. Zhao, Y. Shi, Y. Xi, G.G. Zheng, Y. Yi, and W.P. He (n.d.) A report of 4 cases of severe acute respiratory syndrome patients with suicide tendency. Academic Journal of Second Military Medical University

Duan L, Zhu G (2020) Psychological interventions for people affected by the COVID-19 epidemic. Lancet Psychiatry 7:300-302. https://doi. org/10.1016/s2215-0366(20)30073-0

Dubé M, Le Coupanec A, Wong AHM, Rini JM, Desforges M, Talbot PJ (2018) Axonal transport enables neuron-to-neuron propagation of human coronavirus OC43. J Virol:92. https://doi.org/10.1128/jvi. 00404-18

Dubey D et al (2018) Autoimmune encephalitis epidemiology and a comparison to infectious encephalitis. Ann Neurol 83:166-177. https://doi.org/10.1002/ana.25131

Futch HS, Croft CL, Truong VQ, Krause EG, Golde TE (2017) Targeting psychologic stress signaling pathways in Alzheimer's disease. Mol Neurodegener 12:49. https://doi.org/10.1186/s13024-017-0190-Z

Gao J, Tian Z, Yang X (2020) Breakthrough: chloroquine phosphate has shown apparent efficacy in treatment of COVID-19 associated pneumonia in clinical studies. Biosci Trends 14:72-73. https://doi. org/10.5582/bst.2020.01047

Glaser R, Kiecolt-Glaser JK (2005) Stress-induced immune dysfunction: implications for health. Nat Rev Immunol 5:243-251. https://doi. org/10.1038/nri1571

Hamming I, Timens W, Bulthuis ML, Lely AT, Navis G, van Goor H (2004) Tissue distribution of ACE2 protein, the functional receptor for SARS coronavirus. A first step in understanding SARS pathogenesis. J Pathol 203:631-637. https://doi.org/10.1002/path.1570

Herman JP et al (2016) Regulation of the hypothalamic-pituitaryadrenocortical stress response. Compr Physiol 6:603-621. https:// doi.org/10.1002/cphy.c150015

Hoffmann M et al (2020) SARS-CoV-2 cell entry depends on ACE2 and TMPRSS2 and is blocked by a clinically proven protease inhibitor. Cell 181:271-280.e278. https://doi.org/10.1016/j.cell.2020.02.052

$\mathrm{Hu}$ HJ, Li N (2020) Thirty latest judgments of new coronary pneumonia. Accessed 29 Feb 2020. https://wap.peopleapp.com/article/ rmh11847109/rmh11847109

Huang C et al (2020a) Clinical features of patients infected with 2019 novel coronavirus in Wuhan, China. Lancet (London, England) 395: 497-506. https://doi.org/10.1016/s0140-6736(20)30183-5

Huang JZ, Han MF, Luo TD, Ren AK, Zhou XP (2020b) Mental health survey of 230 medical staff in a tertiary infectious disease hospital for COVID-19. Zhonghua lao dong wei sheng zhi ye bing za zhi = Zhonghua laodong weisheng zhiyebing zazhi $=$ Chinese journal of industrial hygiene and occupational diseases 38:E001. https://doi. org/10.3760/cma.j.cn121094-20200219-00063

Kang L et al (2020) The mental health of medical workers in Wuhan, China dealing with the 2019 novel coronavirus. Lancet Psychiatry 7: e14. https://doi.org/10.1016/s2215-0366(20)30047-x

Karagianni P, Alexopoulos H, Sourdi A, Papadimitriou D, Dimitrakopoulos AN, Moutsopoulos HM (2019) West Nile virus infection triggering autoimmune encephalitis: pathophysiological and therapeutic implications. Clin Immunol 207:97-99 doi:https:// doi.org/10.1016/j.clim.2019.07.007

Kumar A, Rinwa P, Kaur G, Machawal L (2013) Stress: neurobiology, consequences and management. J Pharm Bioallied Sci 5:91-97. https://doi.org/10.4103/0975-7406.111818

Lai CC, Shih TP, Ko WC, Tang HJ, Hsueh PR (2020a) Severe acute respiratory syndrome coronavirus 2 (SARS-CoV-2) and coronavirus disease-2019 (COVID-19): the epidemic and the challenges. Int J Antimicrob Agents 55:105924. https://doi.org/10.1016/j. ijantimicag.2020.105924

Lai J et al (2020b) Factors associated with mental health outcomes among health care workers exposed to coronavirus disease 2019. JAMA Network Open 3:e203976-e203976. https://doi.org/10.1001/ jamanetworkopen.2020.3976

Li YC, Bai WZ, Hashikawa T (2020) The neuroinvasive potential of SARS-CoV2 may play a role in the respiratory failure of COVID19 patients. J Med Virol. https://doi.org/10.1002/jmv.25728

Lin YS et al (2005) Antibody to severe acute respiratory syndrome (SARS)-associated coronavirus spike protein domain 2 crossreacts with lung epithelial cells and causes cytotoxicity. Clin Exp Immunol 141:500-508. https://doi.org/10.1111/j.1365-2249.2005. 02864.x

Mao L, Jin H, Wang M, Hu Y, Chen S, He Q, Chang J, Hong C, Zhou Y, Wang D, Miao X, Li Y, Hu B (2020) Neurologic manifestations of hospitalized patients with coronavirus disease 2019 in Wuhan, China. JAMA Neurol. https://doi.org/10.1001/jamaneurol.2020. 1127

Maunder RG (2009) Was SARS a mental health catastrophe? Gen Hosp Psychiatry 31:316-317. https://doi.org/10.1016/j.genhosppsych. 2009.04.004

Moriguchi T et al (2020) A first case of meningitis/encephalitis associated with SARS-Coronavirus-2. Int J Infect Dis. https://doi.org/10.1016/ j.ijii.2020.03.062

Noisakran S, Halford WP, Veress L, Carr DJ (1998) Role of the hypothalamic pituitary adrenal axis and IL-6 in stress-induced reactivation of latent herpes simplex virus type 1. J Immunol 160:5441-5447

Patel A, Jernigan DB (2020) Initial public health response and interim clinical guidance for the 2019 novel coronavirus outbreak - United States, December 31, 2019-February 4, 2020. MMWR Morb Mortal Wkly Rep 69:140-146. https://doi.org/10.15585/mmwr.mm6905e1

Petersen E et al (2020) Li Wenliang, a face to the frontline healthcare worker. The first doctor to notify the emergence of the SARS-CoV2, (COVID-19), outbreak. Int J Infect Dis 93:205-207. https://doi. org/10.1016/j.ijid.2020.02.052

Prasad A, Chaichi A, Kelley D, Francis J, Gartia MR (2019) Current and future functional imaging techniques for post-traumatic stress disorder RSC. Advances. https://doi.org/10.1039/c9ra03562a

Ryan J, Chaudieu I, Ancelin ML, Saffery R (2016) Biological underpinnings of trauma and post-traumatic stress disorder: focusing on genetics and epigenetics. Epigenomics 8:1553-1569. https://doi.org/ 10.2217/epi-2016-0083

Sanders J, Nemeroff C (2016) The CRF system as a therapeutic target for neuropsychiatric disorders trends. Pharmacol Sci 37:1045-1054. https://doi.org/10.1016/j.tips.2016.09.004

Skinner D, Marro BS, Lane TE (2019) Chemokine CXCL10 and coronavirus-induced neurologic disease. Viral Immunol 32:25-37. https://doi.org/10.1089/vim.2018.0073

Skopouli FN, Katsiougiannis S (2018) How stress contributes to autoimmunity-lessons from Sjögren's syndrome. FEBS Lett 592: 5-14. https://doi.org/10.1002/1873-3468.12933

Soria V et al (2018) Targeting hypothalamic-pituitary-adrenal axis hormones and sex steroids for improving cognition in major mood disorders and schizophrenia: a systematic review and narrative synthesis. Psychoneuroendocrinology 93:8-19. https://doi.org/10.1016/ j.psyneuen.2018.04.012 
Tong ZD et al (2020) Potential presymptomatic transmission of SARSCoV-2, Zhejiang Province, China, 2020. Emerg Infect Dis 26:10521054. https://doi.org/10.3201/eid2605.200198

Wang D, Hu B, Hu C, Zhu F, Liu X, Zhang J, Wang B, Xiang H, Cheng Z, Xiong Y, Zhao Y, Li Y, Wang X, Peng Z (2020) Clinical characteristics of 138 hospitalized patients with 2019 novel coronavirusinfected pneumonia in Wuhan, China. JAMA 323:1061. https:// doi.org/10.1001/jama.2020.1585

Wu F et al (2020) A new coronavirus associated with human respiratory disease in China. Nature 579:265-269. https://doi.org/10.1038/ s41586-020-2008-3

Xiang P et al (2020) First case of 2019 novel coronavirus disease with encephalitis. ChinaXiv T20200300015

Xiao H, Zhang Y, Kong D, Li S, Yang N (2020) The effects of social support on sleep quality of medical staff treating patients with coronavirus disease 2019 (COVID-19) in January and February 2020 in China. Medical science monitor : international medical journal of experimental and clinical research 26:e923549. https://doi.org/10. $12659 / \mathrm{msm} .923549$

Xu K et al (2020a) Management of corona virus disease-19 (COVID-19): the Zhejiang experience. Zhejiang da xue xue bao Yi xue ban = journal of Zhejiang University medical sciences 49

Xu XW, Wu XX, Jiang XG, Xu KJ, Ying LJ, Ma CL, Li SB, Wang HY, Zhang S, Gao HN, Sheng JF, Cai HL, Qiu YQ, Li LJ (2020b) Clinical findings in a group of patients infected with the 2019 novel coronavirus (SARS-Cov-2) outside of Wuhan, China: retrospective case series. BMJ 368:m606. https://doi.org/10.1136/bmj.m606

Yan C et al (2020) Disturbed yin-Yang balance: stress increases the susceptibility to primary and recurrent infections of herpes simplex virus type 1. Acta Pharm Sin B 10:383-398. https://doi.org/10. 1016/j.apsb.2019.06.005

Yang SL, Liu LJ, Dai L, Zhang C, Li JT, Chen C, Liu H (2003) Analysis of anxiety in 78 SARS patients. Nanfang Journal of Nursing 10:2728

Yang YH, Huang YH, Chuang YH, Peng CM, Wang LC, Lin YT, Chiang BL (2005) Autoantibodies against human epithelial cells and endothelial cells after severe acute respiratory syndrome (SARS)-associated coronavirus infection. J Med Virol 77:1-7. https://doi.org/10. 1002/jmv.20407

Zhang L, Liu Y (2020) Potential interventions for novel coronavirus in China: a systematic review. J Med Virol 92:479-490. https://doi.org/ 10.1002/jmv.25707

Zhang JJ, Dong X, Cao YY, Yuan YD, Yang YB, Yan YQ, Akdis CA, Gao YD (2020) Clinical characteristics of 140 patients infected with SARS-CoV-2 in Wuhan, China. Allergy. https://doi.org/10.1111/all. 14238

Zhou P et al (2020) A pneumonia outbreak associated with a new coronavirus of probable bat origin. Nature 579:270-273. https://doi.org/ 10.1038/s41586-020-2012-7

Zou L et al (2020) SARS-CoV-2 viral load in upper respiratory specimens of infected patients. N Engl J Med 382:1177-1179. https://doi.org/ 10.1056/NEJMc2001737

Publisher's Note Springer Nature remains neutral with regard to jurisdictional claims in published maps and institutional affiliations. 